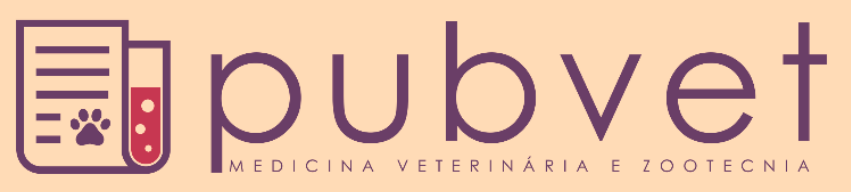

https://doi.org/10.31533/pubvet.v15n07a867.1-15

\title{
Neonatologia canina: manejo e particularidades fisiológicas
}

\author{
Beatriz Souza Vezzali ${ }^{1}$, Aline Ambrogi Franco Prado ${ }^{2} \bullet$, Juliana Izzo Octaviano ${ }^{2} \bullet$ \\ ${ }^{I}$ Médica Veterinária, Fundação Municipal de Ensino Superior de Bragança Paulista, SP, Brasil \\ ${ }^{2}$ Professora da Fundação Municipal de Ensino Superior de Bragança Paulista, SP, Brasil \\ *Autor para correspondência, E-mail:vezzalibeatriz@yahoo.com.br
}

\begin{abstract}
Resumo. A neonatologia aborda os cuidados com o neonato e suas particularidades fisiológicas, além das afecções que os atingem. Neste período ocorrem diversas mudanças e adaptações fisiológicas, metabólicas e anatômicas para estabelecer sua vida no ambiente extrauterino, o que permitirá que o neonato se desenvolva lentamente, e por conta disso apresente imaturidade dos sistemas orgânicos. A negligência em conjunto com a falta de conhecimento básico em fisiologia neonatal canina por parte dos médicos veterinários pode alavancar a crescente taxa de mortalidade neonatal, além do manejo deficiente por parte de médicos veterinários, tutores e criadores. Conhecer as particularidades fisiológicas dos neonatos caninos é onde estão contidos os segredos para que não se perca nenhum neonato visando promover a sua saúde por meio de práticas de higiene e fornecimento de tudo que estes animais precisam na primeira fase de sua vida, ocasionando a queda da mortalidade neonatal, tendo em vista que ela não deve ser considerada algo normal e esperado.
\end{abstract}

Palavras-chave: Neonatologia, neonatos, manejo neonatal, reanimação neonatal

\section{Canine neonatology: handling and physiological particularities}

\begin{abstract}
Neonatology is that addresses the new-born's care and its physiological particularities, in addition to the conditions that affect them. In this period, several physiological, metabolic and anatomical changes and adaptions occur in order to establish its life in the extrauterine environment, which will allow the new-born to develop slowly and, for this reason, present immaturity in the organic systems. The negligence, associated with the lack of basic knowledge of canine neonatal physiology by veterinarians might leverage the rising number of neonatal mortalities, together with the poor handling made by these veterinarians, tutors and breeders. Knowing the physiological particularities of canine new-borns is the secret behind not losing any of them, aiming to promote their health through practices of hygiene and delivering everything these animals need in the first phase of their lives, resulting in the decrease of neonatal mortality, keeping in sight that it should not be considered as something normal and expected.
\end{abstract}

Key words: Neonatology, new-born, neonatal handling, neonatal reanimation

\section{Introdução}

A neonatologia é um ramo da esquiminiatria veterinária (do grego skimnos = animal jovem; iatros = médico) que aborda os cuidados com o neonato e suas particularidades fisiológicas, além das afecções que os atingem (Lourenço, 2015; Prats et al., 2005). O estudo da neonatologia canina vem ganhando espaço entre o público que trabalha com criações de cães, pois desperta conhecimento e curiosidade sobre o assunto. Segundo Nelson \& Couto ( $\underline{2015})$, o significativo valor financeiro e emocional de cães reprodutores, cadelas matrizes e suas crias torna repudiante o fato de haver perdas neonatais por falta de assistência veterinária. Criadouros em geral devem buscar maximizar a sobrevivência neonatal por razões financeiras e éticas. 
Além disso, o Instituto Brasileiro de Geografia e Estatística (IBGE, 2013), em uma Pesquisa Nacional de Saúde, trouxe informações sobre a população de animais pertencentes as famílias brasileiras tanto da área urbana, como na área rural, evidenciando que 44,3\% dos domicílios no Brasil, ou seja, quase metade dos lares brasileiros, possui pelo menos um cachorro, o que confere 28,9 milhões de residências. A partir disso, é interessante levar cada vez mais informações para pessoas que estão diretamente em contato com criações de cães e também para tutores que venham a possuir uma cadela gestante em casa, visando o maior cuidado possível com a mãe e seus filhotes, com o objetivo de impedir a perda dos neonatos. Para isso, é necessário o envolvimento de médicos veterinários com conhecimento básico na área da neonatologia canina para serem capazes de auxiliar os criadores e os tutores, passando informações coerentes e cabíveis de manejo, além das responsabilidades, como aumentar o número de nascimentos viáveis pela minimização dos natimortos devido dificuldades no processo de nascimento, e promover maior sobrevida de neonatos durante a sua primeira semana de vida (Nelson \& Couto, 2015).

O maior índice de mortalidade de neonatos ocorre por problemas de manejo básico que interferem na sobrevivência do mesmo, já que estes precisam de atenção redobrada para lhes proporcionar saúde e bem estar através de práticas de higiene, alimentação e acompanhamento diário de suas características, como o seu ganho de peso diário (Feitosa, 2014; Ftitzgerard \& Newquist, 2011). Portanto, o manejo apropriado na neonatologia canina é de extrema importância para a saúde e integridade dos neonatos com o objetivo de diminuir as grandes taxas de mortalidade que tendem a crescer rapidamente diante de fatores que facilitam a morte de neonatos, simplesmente pelo não cumprimento de pequenas e básicas ações durante o nascimento e nas primeiras horas de vida, ou ainda pela falta de conhecimento sobre a fisiologia neonatal canina, bem como para fornecer o devido cuidado ao neonato que venha a apresentar afecções congênitas que sejam incompatíveis com a vida quando não combinado com o auxílio veterinário.

Contudo, a presente revisão tem por objetivo fornecer informações sobre as particularidades dos neonatos caninos e sua fisiologia para estudantes de medicina veterinária, médicos veterinários, tutores e criadores, tendo em vista que todos os neonatos precisam de cuidados especiais de cunho emergencial, visando promover qualidade de vida e solucionar problemas que estes possam vir a apresentar.

\section{Conceito de neonatologia e período neonatal}

A neonatologia é o ramo da pediatria que se dedica ao estudo do feto e do recém-nascido durante e após seu nascimento. Na literatura este período não se mostra como algo concreto e elucidado (Domingos et al., 2008; Jones, 1987). Segundo Silva et al. (2008), a neonatologia é a ciência responsável pelo estudo dos recém-nascidos, e aborda o período neonatal do nascimento até o décimo quarto dia de vida, ou seja, as duas primeiras semanas após o nascimento, concordando com Sorribas (2007).

Grundy (2006) interpreta o período neonatal em cães como sendo as primeiras quatro semanas de vida, e justifica por coincidir com o momento em que ocorre o desmame. Macintire et al. (2007) defende que os filhotes são considerados neonatos do nascimento até duas semanas de vida. Kustritz (2011) aborda o período neonatal do nascimento até três semanas de vida, ou quando o filhote é capaz de andar, urinar e defecar espontaneamente. Feitosa (2014) define o período neonatal canino como sendo o intervalo em que o filhote ainda tem certa dependência aos cuidados maternos para a sua sobrevivência, e concorda com Grundy (2006) afirmando que este período compreende os trinta primeiros dias de vida. Neste período ocorrem diversas mudanças e adaptações fisiológicas, metabólicas e anatômicas para estabelecer sua vida no ambiente extrauterino, o que permitirá que o neonato se desenvolva lentamente, e por conta disso apresente imaturidade dos sistemas orgânicos (Feitosa, 2014). Na primeira semana de vida, os neonatos caninos dedicam $70 \%$ do seu tempo para dormir e 30\% para mamar, e dependem $100 \%$ da mãe para se alimentarem, urinarem e defecarem. A abertura do pavilhão auricular se dá entre 12 e 14 dias após o nascimento, assim como na Figura 1, e a abertura dos olhos ocorre entre 10 e 14 dias de vida, como mostra a Figura 2 (Sorribas, 2007).

O começo da independência dos filhotes acontece a partir da $3^{\mathrm{a}}$ semana de vida, quando são capazes de andar, urinar e defecar espontaneamente, há desenvolvimento dos dentes decíduos, são capazes de regular a própria temperatura e já apresentam o olfato apurado (Sorribas, 2007). 


\section{Mortalidade neonatal canina}

Definido o período neonatal, é preciso então destacar que devido essas alterações de ambiente e mudanças fisiológicas que o neonato sofre, seu manejo ocorre de forma distinta do manejo de costume que se coloca em prática com os animais adultos ( Kustritz, 2011). Grundy (2006) afirma que a chave para a desmistificação dos cuidados neonatais caninos é não considerar estes pacientes como adultos em miniatura, e buscar definir tratamentos adequados à sua fisiologia ímpar.

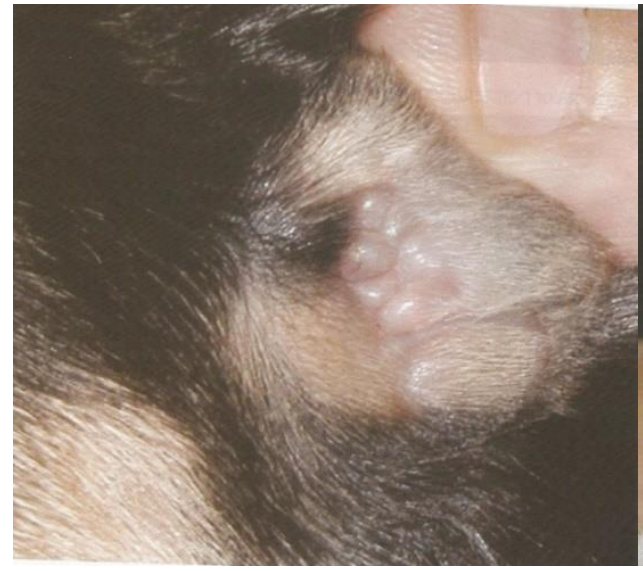

Figura 1. O pavilhão auricular abre-se entre o $12^{\circ}$ e $14^{\circ}$ dias. Fonte: Sorribas (2007)

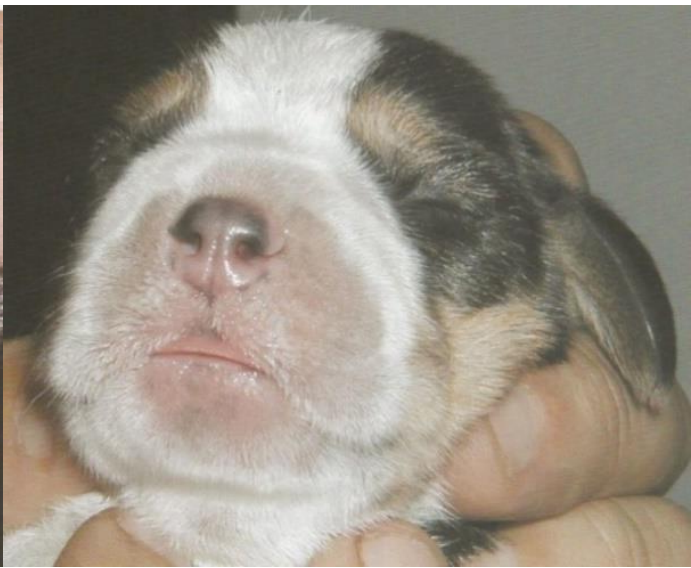

Figura 2. Abertura das pálpebras ocorre entre o $10^{\circ} \mathrm{e}$ $14^{\circ}$ dias. Fonte: Sorribas (2007)

A negligência em conjunto com a falta de conhecimento básico em fisiologia neonatal canina por parte dos médicos veterinários pode alavancar a crescente taxa de mortalidade neonatal, além do manejo deficiente por parte de médicos veterinários, tutores e criadores (Peterson \& Kutzler, 2011).

Ftitzgerard \& Newquist (2011) estabelecem que nenhum período da vida de um organismo vivo requer tantos cuidados como na fase neonatal. Portanto, é fundamental ter domínio das muitas características neonatais fisiológicas e anatômicas que diferem rigorosamente dos adultos.

Segundo Tønnessen et al. (2012), a mortalidade neonatal é definida pela morte do filhote após o nascimento, e pode ser classificada como mortalidade neonatal precoce quando as mortes ocorrem nos primeiros sete dias de vida, e tardia cujas mortes ocorrem de sete a 28 dias após o nascimento. A taxa de mortalidade neonatal em cães diminui à medida que o neonato cresce e se desenvolve, tendo como estatísticas $75 \%$ das mortes em filhotes nas três primeiras semanas de vida, 50\% das mortes neonatais ocorrendo em até três dias após o nascimento e 65\% de mortalidade na primeira semana de vida (Peterson \& Kutzler, 2011). Angulo (2012) afirma que em partos assistidos por médicos veterinários há uma queda significativa na mortalidade neonatal.

O nascimento é o processo que exige mais disposição e comprometimento por parte do neonato em toda a sua vida, pois neste momento ocorrerá a transição fetal-neonatal definindo uma situação consideravelmente perigosa, devido todas as adaptações que sofrerá (Landim-Alvarenga et al., 2017). Segundo Feitosa (2014), há uma relação forte entre as mortes neonatais e possíveis causas ambientais. Portanto, é imprescindível disponibilizar um local de parto que a cadela já esteja habituada, sendo seguro para que os filhotes não sofram episódios de canibalismo ou pisoteamento, além de impedir a fuga destes. A área do parto deve ser seca, arejada, isenta de insetos e contendo uma altura que permita a circulação da cadela com facilidade (Lourenço, 2015). Dentre causas de óbitos de neonatos caninos subestimadas estão fome, hipotermia, problemas de manejo, desidratação, traumas, descaso ou desconhecimento e falta de orientação para o tutor (Peterson \& Kutzler, 2011).

\section{Fisiologia e manejo neonatal canino}

\section{Sistema respiratório e adaptação}

Durante a gestação, os pulmões fetais encontram-se colabados sem realizar trocas gasosas, pois nessa fase de vida intrauterina, o feto utiliza oxigênio de origem materna que se espalha na circulação fetal por via placentária (Lourenço \& Machado, 2013). O parto promove uma situação de estresse para o 
neonato, no qual ocorre um breve momento de asfixia devido baixos níveis de surfactante presente no pulmão no momento do nascimento, onde o neonato deve lançar mão de seu primeiro movimento respiratório que se caracteriza por uma profunda inspiração com o intuito de extinguir a atelectasia dos seus pulmões imaturos. Neste momento, o neonato fica responsável por fazer a troca da substância líquida presente nos alvéolos por conteúdo aéreo (Lourenço \& Machado, 2013).

Landim-Alvarenga et al. (2006) salientam que as vias respiratórias superiores do neonato logo após o nascimento devem estar escassas de conteúdo líquido, muco, mecônio e sem indícios de anexos fetais e fluidos placentários. Caso contrário, o profissional responsável por inspecionar o local pode fazer a retirada destes com os dedos enluvados, ou ainda, como melhor escolha, utilizar de sistema de sucção próprio para esta manobra, assim como mostra a Figura 3 (McMichael, 2011).

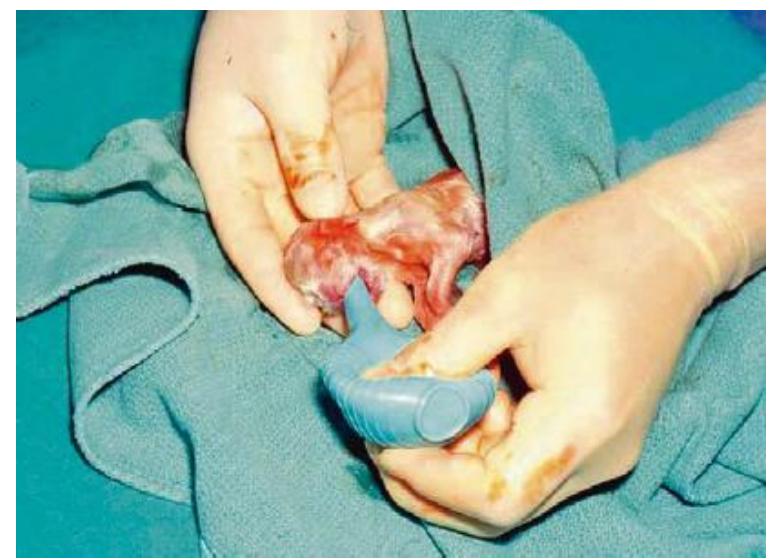

Figura 3. Uso de pêra de sucção para delivramento das vias aéreas. Fonte: MiMichael (2011).

A frequência respiratória do neonato um dia após o nascimento varia de 10 e 18 movimentos por minuto, e na primeira semana de vida fica entre 16 a 32 movimentos por minuto (mpm) (Feitosa, 2014).

\section{Ausência de termorregulação independente}

Os neonatos caninos são classificados como pecilotérmicos por não possuírem controle hipotalâmico desenvolvido suficientemente para realizar termorregulação (Feitosa, 2014). A temperatura retal normalmente diminui logo após o nascimento, provavelmente como uma adaptação para proteger os neonatos da hipóxia e acidose, reduzindo a demanda metabólica (Lawler, 2008). Recebem essa classificação, pois dependem da temperatura do ambiente para manter a sua temperatura corpórea, sendo necessária uma fonte de calor, sendo ela materna ou fornecida, tal qual garrafas de água quente como exemplo podendo ser visto na Figura 4 (Barreto, 2003). Temperaturas ambientais incorretas podem ter efeitos devastadores nos neonatos (Peterson \& Kutzler, 2011). Segundo Landim-Alvarenga et al. (2006), a temperatura ambiente adequada para que o neonato se adapte deve estar em torno de 30 a $32^{\circ} \mathrm{C}$.

São considerados pecilotérmicos até completarem o primeiro mês de vida. O controle da temperatura só se estabelece após 7 a 9 dias através de mecanismos controladores de tremor e vasoconstrição (Apparício et al., 2015; Landim-Alvarenga et al., 2017).

Devido à imaturidade do sistema termorregulador que pertence ao sistema nervoso, os neonatos não apresentam reflexo de tremor para fazer a manutenção da sua temperatura corpórea de forma adequada (Barreto, 2003) até os primeiros seis dias de vida, chegando fácil e rapidamente a um quadro de hipotermia (Peterson \& Kutzler, 2011).

Como os neonatos não possuem a capacidade de gerar calor via os tremores, sua produção de calor inicial se dá por lipólise da gordura marrom, que é um tecido composto por numerosas mitocôndrias. Este tipo de tecido adiposo é utilizado até as três semanas de vida, sendo apenas parcialmente capaz de manter a temperatura corporal do neonato em um ambiente com aproximadamente $30^{\circ} \mathrm{C}$ (Miller, 2011).

Outra resposta mais presente, há imaturidade em se termorregular, os neonatos possuem um mecanismo de termotropismo positivo (Figura 5), sendo atraídos por fontes de calor como a mãe e seus 
próprios irmãos (Chaves, 2011; Domingos et al., 2008). Lourenço (2015) especifica que após o aquecimento, o neonato deve ser mantido à temperatura ambiente entre $29,4^{\circ} \mathrm{C}$ e $35,0^{\circ} \mathrm{C}$, sob umidade relativa do ar de 55 a $65 \%$. Esse controle de temperatura e umidade deve ser feito com prudência, pois a massa corpórea do neonato é composta em grande parte por água (70 a 75\%), sendo um fator que influencia diretamente na desidratação do filhote (Jones, 1987). Landim-Alvarenga et al. (2006) definem a temperatura corporal normal do neonato canino como sendo mais baixa que a do adulto. Na primeira semana, deve oscilar entre 35,0 e $37,2^{\circ} \mathrm{C}$; na segunda, entre 36,1 e $37,8^{\circ} \mathrm{C}$; e somente na quarta semana se assemelha à do adulto.

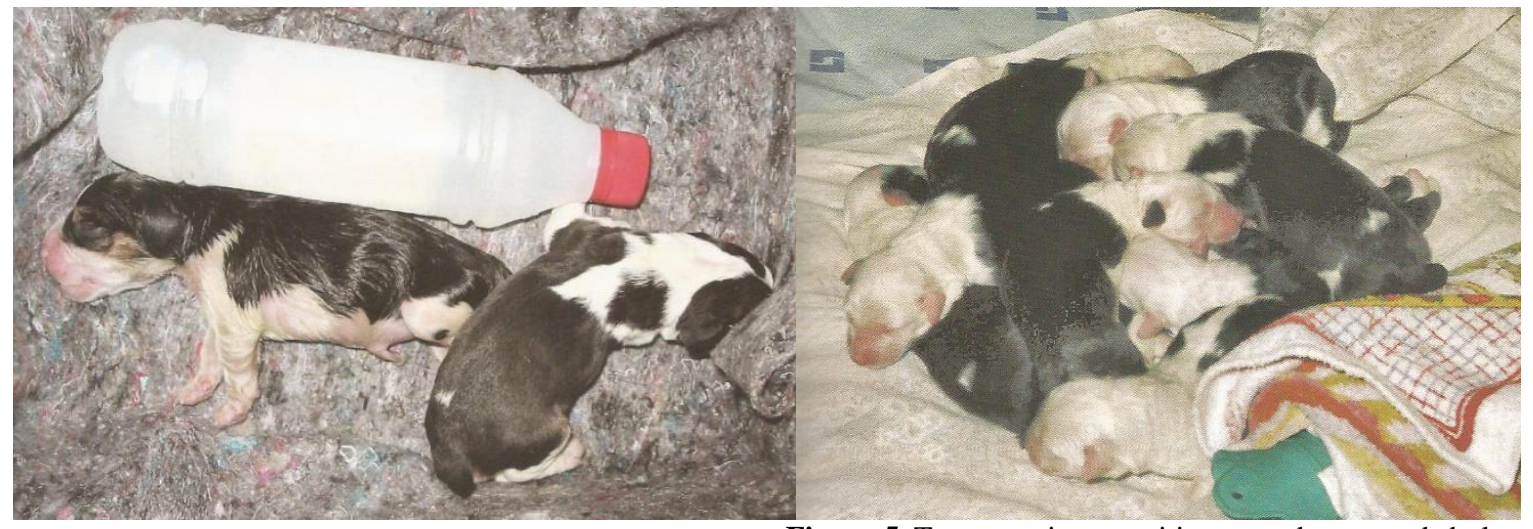

Figura 4. Uso de garrafas com água quente como fonte de calor externa. Fonte: Sorribas (2007)

Figura 5. Termotropismo positivo somado ao uso de bolsa de água quente como fonte de calor externa. Fonte: Sorribas (2007)

Somando o termotropismo positivo e o uso de fontes de calor fornecidas como lâmpadas de calor, bolsas térmicas e garrafas de água aquecidas, é importante salientar que ainda sobre a imaturidade do sistema termorregulador, os neonatos não apresentam reflexo de retirada, o que torna as fontes de calor perigosas podendo causar queimaduras (Figura 6), pois os neonatos não tem consciência do tempo que podem permanecer em contato com elas (Peterson \& Kutzler, 2011).

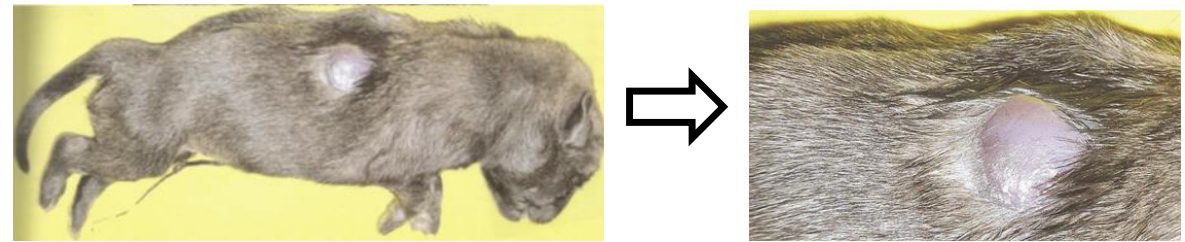

Figura 6. Queimadura na superfície da pele de um neonato causada por excesso de contato com fonte de calor externa. Fonte: Fonte: Sorribas (2007).

\section{Alimentação, ganho de peso e aquisição de imunidade}

O sistema digestório é mais um sistema orgânico que se encontra imaturo no neonato por ter que se responsabilizar por tarefas digestivas que antes eram obrigação da placenta (Feitosa, 2014). Os intestinos dos neonatos apresentam-se estéreis ao nascimento, porém essa característica não dura muito tempo, pois a lambedura fisiológica da mãe feita logo após o nascimento promove a entrada de microorganismos que colonizam os intestinos rapidamente (Apparício et al., 2015). Portanto, é importante que imediatamente após o nascimento, o neonato ingira colostro para que a transferência de imunidade passiva seja feita com total êxito, e este adquira fatores de crescimento e nutrientes necessários para o seu desenvolvimento extrauterino, e impeça que os microrganismos que adentraram à mucosa intestinal causem infecções ao neonato (Apparício et al., 2015).

Landim-Alvarenga et al. (2006) afirmam que para o neonato adquirir imunidade sistêmica adequada, é imprescindível que ingiram o colostro dentro das primeiras 12 horas após o nascimento. Com 16 horas de vida já não é possível a realização da transferência passiva de imunoglobulinas com eficiência total. A imunodeficiência neonatal pode estar presente decorrente da não ingestão ou incorreto consumo do colostro devidamente acompanhado das suas imunoglobulinas, podendo predispor o filhote a infecções

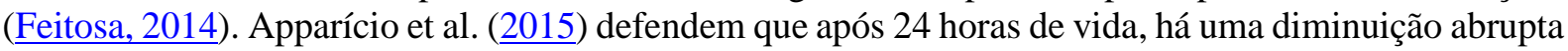


da permeabilidade intestinal do neonato às proteínas do colostro, e isso ocorre em consequência da maturação das células intestinais e estabelecimento da flora intestinal, onde as bactérias que a ela pertencem são capazes de degradar as imunoglobulinas oriundas do colostro, atrapalhando assim a absorção colostral. Por isso, o neonato deve mamar o colostro logo após o nascimento.

Um hemograma contendo níveis de enzimas hepáticas como a gama-glutamiltransferase (GGT), pode revelar se houve ingestão adequada do colostro, pois esta assume uma grande concentração sérica nesse caso, funcionando como um eficiente indicador da absorção colostral (Martins, 2005; Peterson \& Kutzler, 2011).

É interessante que o neonato apresente reflexo de sucção (Figura 7) para que consiga mamar diretamente na mãe, e se caso necessário, seja alimentado por mamadeira ou seringa. O neonato deve ser alimentado a cada 2 a 4 horas durante a primeira semana de vida, e a cada 4 a 6 horas até o desmame (Landim-Alvarenga et al., 2017). A capacidade estomacal do neonato é de $50 \mathrm{ml} / \mathrm{kg}$, e a cada mamada não se pode ultrapassar este volume de alimento (Macintire et al., 2007).

A posição correta para alimentar o neonato via mamadeira é em decúbito esternal, como na Figura $\underline{8}$, e o neonato deve ser capaz de empurrar a mamadeira com os membros anteriores bem como faria caso estivesse amamentando na própria mãe. $O$ neonato não pode estender demais a cabeça durante a mamada, pois isso pode aumentar o risco de aspiração do leite (Peterson \& Kutzler, 2011).

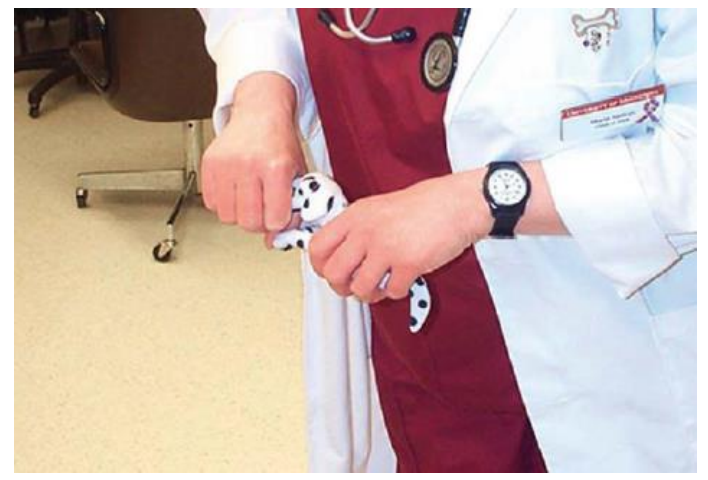

Figura 7. Demonstração do reflexo de sucção em neonatos caninos. Fonte: Kustritz (2011).

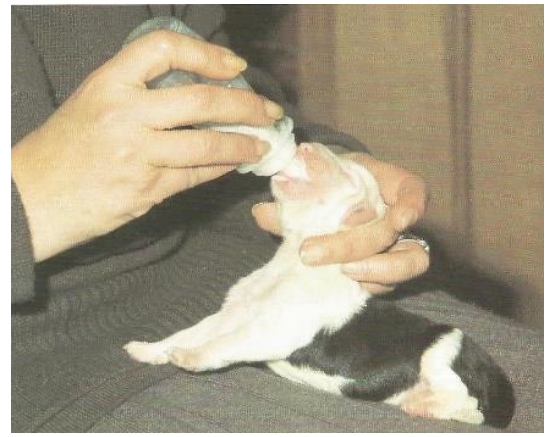

Figura 8. Neonato apoiado sobre os membros e leve inclinação caudal, para facilitar a sucção e diminuir os riscos de uma falsa via. Fonte: Sorribas (2007).

A frequência de alimentação do neonato é grande devido a sua imaturidade hepática e renal, na qual o estoque de glicogênio é muito precário e a gliconeogênese ineficaz ocorrendo no fígado do neonato somente após nove horas sem alimentação, além do metabolismo acelerado do neonato que faz uso de grande parte da glicose disponível, e presença de glicosúria renal fisiológica, pois os túbulos renais ainda não fazem a reabsorção correta de substâncias presentes na urina (Feitosa, 2014).

$\mathrm{O}$ peso ao nascimento representa um fator de risco e fornece prognósticos relevantes relacionados à mortalidade neonatal. Filhotes que apresentam baixo peso ao nascimento e incapacidade em prosperar sua taxa de crescimento, têm grandes chances de vir a óbito nos primeiros três dias de vida (Peterson \& Kutzler, 2011).

O que indica ocorrência de algum tipo de contratempo no desenvolvimento fetal ou a presença de anomalias congênitas é o fato de neonatos nascerem magros, fracos e abaixo do peso que se espera para a raça ou porte. É comum observar filhotes maiores da ninhada retirarem da lactação os filhotes debilitados que nasceram abaixo do peso ideal (Feitosa, 2014). Problemas neonatais de caráter primário em cães geralmente são causados por hipóxia, hipoglicemia, hipotermia, má hidratação, infecção e nutrição inadequada (Peterson \& Kutzler, 2011). A verificação do ganho de peso diário (Figura 9) serve como parâmetro para identificar neonatos que se alimentam corretamente e neonatos que possuem algum déficit na sua alimentação. Isso é feito pela pesagem diária de todos os neonatos antes e depois de cada mamada (Domingos et al., 2008). Vale lembrar que é fisiológico que o neonato perca de 5 a $10 \%$ do seu peso inicial durante o seu primeiro dia de vida, devido uma mínima e esperada desidratação proveniente da defecação que ocorre nas primeiras horas após o nascimento. Depois deste período, é imprescindível que o neonato ganhe peso (Barreto, 2003; Domingos et al., 2008; Feitosa, 2014; Sorribas, 2007). 
Neonatos hipotérmicos não podem ser alimentados. O ideal é que este se encontre em normotermia. A hipotermia promove atonia do trato gastrointestinal diminuindo seu fluxo sanguíneo por conta do desvio de calor para locais do corpo que precisam ser aquecidos. Caso haja o aleitamento do neonato hipotérmico, não haverá absorção do leite e ocorrerá estase deste no trato gastrointestinal pela falta de movimentos peristálticos para expulsa-lo. Então, o leite fermentará promovendo proliferação bacteriana e posterior enterocolite necrosante, caso haja deslocamento bacteriano que desenvolverá necrose de trato gastrointestinal, bacteremia sendo possível uma evolução para sepse (Prendergast, 2011). Após cada mamada, é indispensável que haja um estímulo do reflexo de micção e defecação nos neonatos (Figura 10), mais especificamente na região anogenital, que geralmente é realizado por ação mecânica da mãe através de lambeduras. Caso a cadela não seja capaz de realizar esse estímulo, pode ser feito por médicos veterinários por massagem da área com algodão ou gaze seca ou úmida. Pode-se também utilizar lenços de papel macio, ou simplesmente correr os dedos enluvados ao longo da parede abdominal do filhote (Landim-Alvarenga et al., 2017).

Qualquer neonato que apresente choro constante, no geral indica frio, fome, presença de alguma injúria, mas, em todos os casos, precisa de atenção e assistência imediata (Peterson \& Kutzler, 2011).

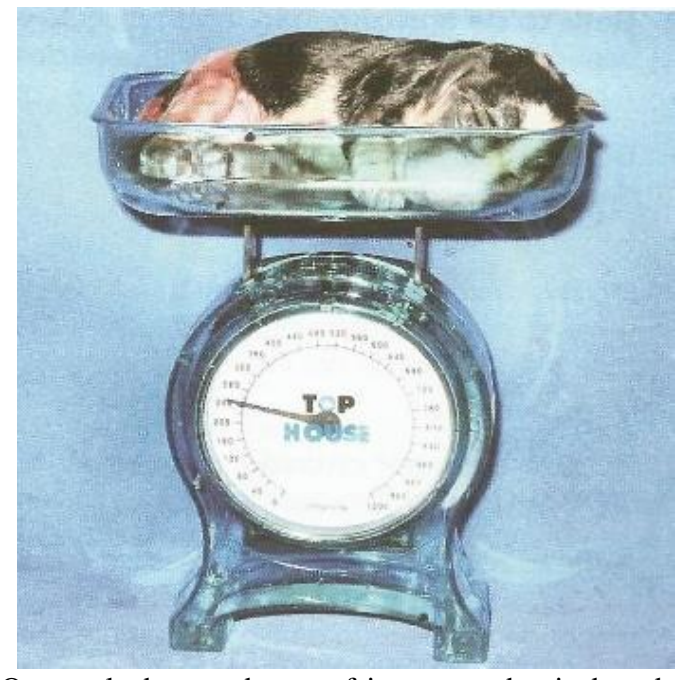

Figura 9. O controle de peso deve ser feito antes e depois de cada mamada para que haja uma monitoração confiável do ganho de peso diário do filhote. Fonte: Sorribas(2007).

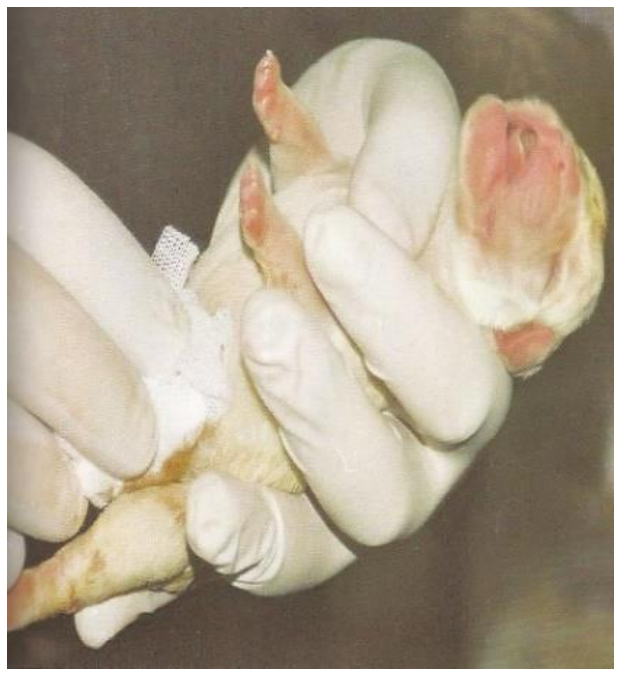

Figura 10. Estimulação do reflexo ano genital. Fonte: Sorribas (2007).

\section{Ambiente adequado para manter os neonatos caninos}

É de extrema importância manter o local limpo para que os filhotes não tenham contato com microorganismos oriundos do ambiente e provenientes da própria mãe, tendo em vista o não desenvolvimento de infecções neonatais. Trocar sempre os materiais utilizados para o conforto dos filhotes e da mãe e higienizando o ambiente, bem como manter a mãe saudável durante toda a gestação e também durante o período de lactação para que ela forneça alimentação de qualidade ao neonato. A sobrevida do neonato tem relação direta com a qualidade do parto (Lourenço, 2015; Nelson \& Couto, 2015). Outro fator que atua como fonte de mortalidade neonatal é a disposição e tamanho adequados da área onde ocorrerá o parto, tendo duas variáveis: local muito grande promovendo afastamento do neonato da mãe e de seus irmãos resultando em hipotermia do filhote; e local muito pequeno trazendo riscos de o neonato ser esmagado pela mãe (Peterson \& Kutzler, 2011).

Landim-Alvarenga et al. (2017) destacam a cura do umbigo como momento da vida do neonato que pede uma rigorosa higiene que deve ser feita com muita cautela higienizando o local com solução antisséptica seguida de secagem e aplicação de tintura de iodo, sendo também uma opção usar spray antibiótico, pois o cordão umbilical e o umbigo são principais portas de entrada para patógenos e microorganismos capazes de promover sepse.

Na Figura 11 é possível ver o umbigo de um neonato canino 48 horas após o nascimento, sendo que Sorribas (2007) indica a inspeção e higiene do umbigo duas vezes ao dia, ocorrendo a queda do cordão 
umbilical por volta de 72 horas após o nascimento, onde a cicatriz deve ser inspecionada até a cura completa.

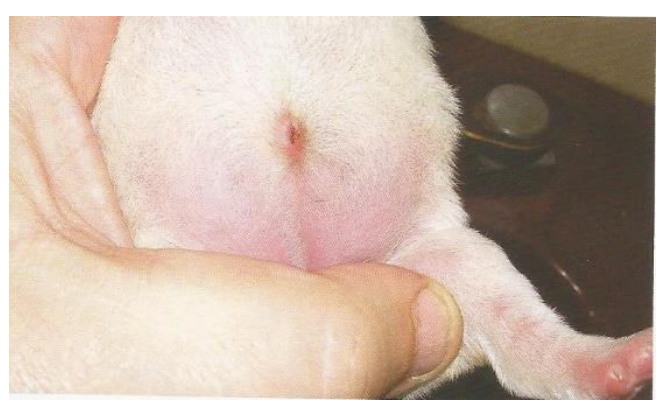

Figura 11. Umbigo 48 horas após o nascimento. Fonte: Sorribas (2007).

\section{Cuidados com neonatos órfãos}

Nos casos em que os pacientes neonatos são considerados órfãos, deve-se levar em consideração o conceito de orfandade, visto que existem os órfãos "verdadeiros", os quais a mãe não foi capaz de oferecer nenhum tipo de cuidado ao filhote por fatores como falta de instinto materno, ou por vir a óbito. Os órfãos parciais são aqueles que apresentam algum tipo de limitação, como a fenda palatina por parte do neonato, ou a falta de leite materno, e por conta desses fatores, necessitam de cuidados além dos oferecidos pela mãe através de uma complementação no manejo (Peterson \& Kutzler, 2011).

Dentre situações em que os filhotes precisam ser tratados como órfãos estão prematuridade, hipogalactia ou agalactia, tríade neonatal, mastite, ninhada numerosa, morte da mãe, alterações congênitas, falha do extinto materno, filhotes de baixo peso, necessidade de internação do filhote, abandono, entre outras (Peterson \& Kutzler, 2011). Nestes casos é preciso desempenhar todo o papel da mãe, desde alimentação, aquecimento, estímulos para urinar e defecar, promover imunidade. Essas responsabilidades maternas podem ser feitas da mesma forma de manejo que foram tratados nos tópicos anteriores, bem como o uso de banco de colostro e outras formas de imunização para promover imunidade ao neonato órfão, já que este não teve acesso ao colostro da mãe rico em imunoglobulinas essenciais para a sua sobrevivência e desenvolvimento (Peterson \& Kutzler, 2011).

É sempre indicado o uso de substituto do leite em forma comercial, pois este contém a quantidade correta de proteínas, gorduras, carboidratos, vitaminas e minerais que os neonatos caninos precisam para o seu crescimento (Prendergast, 2011). Quando o substituto comercial do leite estiver temporariamente indisponível, pode-se fazer uso de receitas caseiras para alimentar os filhotes órfãos, porém devem ser utilizadas somente para casos de emergência, e devem ser trocadas para a fórmula láctea comercial o mais rápido possível (Prendergast, 2011). Peterson \& Kutzler (2011) afirmam que, segundo estudos, receitas caseiras mesmo quando administradas em volumes maiores ou com frequência maior, podem resultar em taxas de crescimento mais lentas quando comparadas com as taxas de crescimento em neonatos caninos alimentados com fórmulas comerciais. Segundo Prendergast (2011), a receita caseira apresentada no Quadro 1 rende aproximadamente $1,2 \mathrm{kcal} / \mathrm{ml}$, ou seja, em um neonato canino com cerca de $400 \mathrm{~g}$ de peso seria alimentado com esta receita com aproximadamente $60 \mathrm{ml} /$ dia divididos em 8 mamadas ao longo do dia.

Quadro 1. Fórmula caseira de leite de cadelas para suplemento lácteo para cães.

\begin{tabular}{lc}
\hline Ingredientes & Quantidade \\
\hline Leite integral de vaca & $115 \mathrm{ml}$ \\
Água & $115 \mathrm{ml}$ \\
Gema de ovo & 2 \\
Carbonato de cálcio & $500 \mathrm{mg}$ \\
Óleo vegetal & 1 colher de chá \\
\hline
\end{tabular}

Fonte: adaptado de Prendergast (2011).

A alimentação deste filhote deve ser feita com mamadeira ou seringa quando este apresentar reflexo de sucção. Em casos de presença de fenda palatina, faz-se necessária a sondagem oro-gástrica (Figura 12), que deve ser introduzida pela boca lentamente para estimular a deglutição do filhote que vai contribuir para a entrada facilitada da sonda (Peterson \& Kutzler, 2011; Sorribas, 2007) 
O Quadro 2 mostra os principais problemas que podem acometer neonatos caninos quando se realiza o uso de alimentação artificial e quais sinais clínicos estes pacientes podem apresentar, segundo Peterson $\&$ Kutzler (2011).

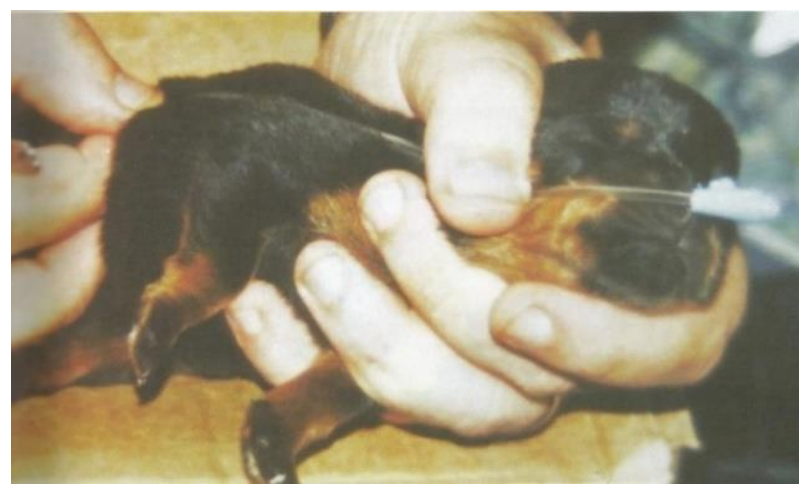

Figura 12. Para calcular o comprimento da sonda oro-gástrica mede-se da boca até a borda do gradil costal. Fonte: Sorribas (2007).

Quadro 2. Principais problemas que os neonatos caninos podem desenvolver na alimentação artificial e sinais clínicos associados.

\begin{tabular}{lc}
\hline Problemas & Sinais clínicos \\
\hline Posicionamento errado & > Risco de aspiração \\
Temperatura incorreta & Hipotermia, queimaduras, falha na digestão \\
Administração errada & Vômito, cólica, inchaço \\
Falha na preparação & Diarreia, inchaço, desnutrição \\
Pouca higiene & Diarreia, vômito, infecção \\
\hline
\end{tabular}

Fonte: adaptado de Peterson \& Kutzler (2011).

\section{Principais alterações que podem afetar os neonatos caninos}

\section{Hipóxia}

A maior causa de mortalidade neonatal não infecciosa é a hipóxia neonatal que pode ocorrer como resultado de distocias, baixos níveis de surfactante, atelectasia, aspiração de mecônio ou restos de anexos fetais, anemia, entre outros (Peterson \& Kutzler, 2011). A Figura 13 de Sorribas (2007) mostra a nítida diferença entre um neonato canino em hipóxia e um neonato canino hígido.

É essencial que as bolsas que envolvem o feto não se rompam no momento do parto para que o neonato não as inspire acidentalmente, evitando com sucesso que a hipóxia se desenvolva (Angulo, 2012).

\section{Tríade neonatal}

A tríade neonatal é uma das principais condições que ocorrem no período atingindo neonatos descompensados e sempre se manifesta por consequência de alguma patologia ou anormalidade da sua condição fisiológica, capaz de levar ao óbito rapidamente. É composta por hipotermia, hipoglicemia e desidratação do neonato, que podem ser causadas por um manejo inadequado. A hipotermia se desenvolve com facilidade nos neonatos por conta da sua incapacidade de produzir calor, justamente por apresentarem mecanismo de termorregulação ineficiente e ausência do reflexo de tremor. Geralmente se manifesta quando não há uma fonte de calor para o neonato regular sua temperatura (Apparício et al., 2015; Feitosa, 2014). Para corrigir a hipotermia do neonato, monitorar frequentemente a temperatura deste é fundamental para evitar um superaquecimento. (Macintire et al., 2007). O aquecimento deve ser feito de forma lenta, promovendo o aumento de $1^{\circ} \mathrm{C}$ por hora. Caso ocorra um aumento de $2^{\circ} \mathrm{C}$ ou mais por hora, o neonato pode apresentar falência de órgãos vitais, como coração e rins (Peterson \& Kutzler, 2011).

A glicemia dos neonatos caninos do nascimento até as duas semanas de vida varia entre 111 e 146 $\mathrm{mg} / \mathrm{dL}$. Quando atingem a idade de duas a quatro semanas de vida, a glicemia de um neonato hígido pode estar no intervalo de 86 a $115 \mathrm{mg} / \mathrm{dL}$ (Kustritz, 2011). A hipoglicemia se dá pela baixa concentração de glicogênio hepático e carência de um potencial enzimático adequado necessário para promover gliconeogênese, que se mantém dessa forma até os primeiros 10 dias de vida. Em geral afeta 
os neonatos que não mamam o colostro corretamente, promovendo o uso das reservas energéticas escassas dos neonatos para mantê-los em glicemia regular. Nos neonatos hipoglicêmicos, a glicose pode ser administrada por via oral (Apparício et al., 2015; Feitosa, 2014; Macintire et al., 2007).

Alguns sinais clínicos que os neonatos caninos apresentam quando estão em quadro de hipoglicemia são choro incessante, fraqueza, tremores, coma e convulsões (Peterson \& Kutzler, 2011). A desidratação se estabelece nos neonatos em virtude da sua superfície corpórea ser grande em relação ao seu peso (18\% do peso corporal), $80 \%$ do corpo do neonato ser composto por água, e em razão da imaturidade renal fisiológica do neonato, e por isso, é necessária uma fluidoterapia maior que a básica diária de 13 a $22 \mathrm{ml}$ para cada 100 gramas de peso corporal para que estes saiam do quadro de desidratação. A Figura $\underline{14}$ mostra a não confiabilidade no turgor cutâneo como parâmetro vital de resposta imediata, devido às particularidades que os neonatos caninos apresentam. Estes só apresentarão grau de desidratação consideravelmente visível em exame de turgor cutâneo quando este for irreversível. Geralmente, a desidratação ocorre em locais onde não se tem uma fonte de umidade no ambiente (Apparício et al., 2015; Macintire et al., 2007).

A administração de fluidos aquecidos a $37^{\circ} \mathrm{C}$ tem papel importante na manutenção da temperatura dos neonatos, sendo interessante o uso do acesso intravenoso pela veia jugular, com o fluido sendo aplicado em velocidade de $1 \mathrm{ml}$ a cada 30 gramas de peso por 5 a 10 minutos, sendo repetida em intervalos de 30 minutos (Macintire et al., 2007).

\section{Fenda palatina}

A fenda palatina, também conhecida por palatosquise, é uma anomalia do desenvolvimento que se caracteriza pela fenda no palato que faz com que haja uma comunicação entre as cavidades oral e nasal (Figura 15). Apesar de ser uma alteração compatível com a vida, alguns cães neonatos morrem precocemente devido à aspiração de leite e consequente pneumonia aspirativa (Lopes et al., 2007; McGavin \& Zachay, 2013; Zachary et al., 2012). Quando o neonato apresenta este defeito congênito, não é capaz de manter um reflexo de sucção adequado, havendo possibilidade de aspiração do leite para as vias aéreas durante a ingestão, resultando em pneumonia aspirativa (Feitosa, 2014; Ruaux, 2011). Neste caso, até que o filhote atinja idade suficiente para a cirurgia, este deve ser alimentado via sondagem oro-gástrica (Sorribas, 2007).

Segundo Apparício et al. (2015) a cirurgia reparadora normalmente é feita quando o animal alcança uma idade segura para ser exposto a uma anestesia, ou seja, ao atingir três meses de vida, quando estes já são capazes de se alimentar sozinhos. Por sua vez, Ruaux (2011) diz que se deve esperar até que os filhotes atinjam por volta de 16 semanas de idade, quando já houve maturação da cavidade oral por completo.

\section{Sepse}

A sepse é a principal causa infecciosa de morte neonatal que muitas vezes se inicia, por exemplo, por uma pneumonia, onfalite ou enterite de bactérias advindas do próprio ambiente que o neonato vive. Por isso, não é incomum encontrar na clínica um recém-nascido que necessita de antibioticoterapia. A onfalite pode ser causada pelas manobras que a mãe faz com o neonato na região umbilical, como a lambedura excessiva, promovendo fissuras no cordão umbilical e facilitando a entrada de bactérias presentes na pele da mãe, na glândula mamária e também no ambiente, resultando em um quadro de sepse ( Souza et al., 2017).

O tratamento para sepse em neonatos caninos é feito a partir de fluidoterapia para fornecer hidratação, reposição da glicose, sendo esta monitorada a cada 4 a 6 horas precisando permanecer dentro de um intervalo de 80 a $250 \mathrm{mg} / \mathrm{dL}$. Também se usa antibióticos específicos vindo de antibiograma previamente feito, porém muitas vezes não se tem tempo para aguardar os resultados, fazendo com que o médico veterinário escolha um antibiótico de maior espectro para maior segurança no tratamento. Além disso, aplica-se formas de aquecimento externo, oxigenação, alimentação via sonda orogástrica e monitoração constante (Macintire et al., 2007). 


\section{Anasarca}

A anasarca, também conhecida como hidropsia fetal, é caracterizada pelo acúmulo de líquido em excesso no subcutâneo, pode ser vista na Figura 16, promovendo a formação de um abcesso generalizado em toda a superfície corpórea do neonato, com efusão pleural e peritoneal, fazendo o filhote apresentar o dobro do seu peso normal esperado para o nascimento (Apparício et al., 2015).

O tratamento pode ser feito com administração de furosemida a cada 3 horas para diminuir o edema em conjunto com o estímulo de micção. Também fornecer potássio em gotas para evitar perda excessiva desse mineral como consequência da ação do diurético. Ainda assim, o prognóstico para este quadro é considerado de reservado a grave (Sorribas, 2007).

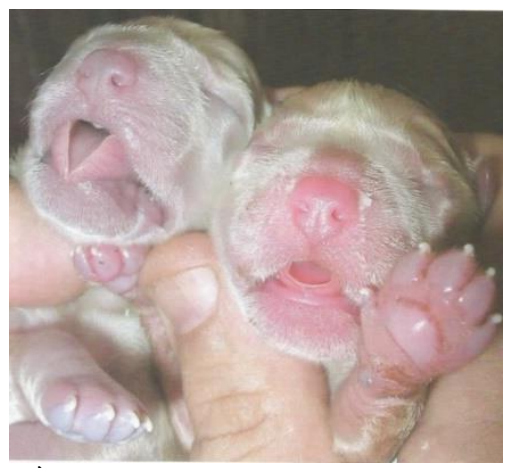

Figura 13: À esquerda um neonato apresentando hipóxia, onde se observa a coloração cianótica das mucosas. À direita, um neonato hígido. Fonte: Sorribas (2007).

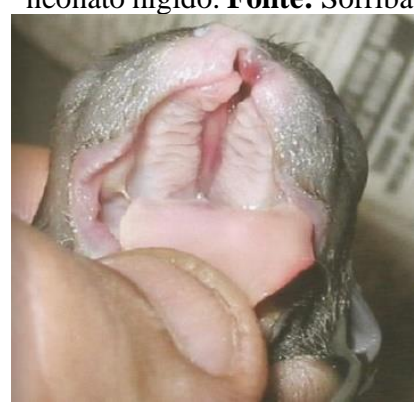

Figura 15. Filhote com fenda palatina e lábio leporino. Fonte: Sorribas (2007)

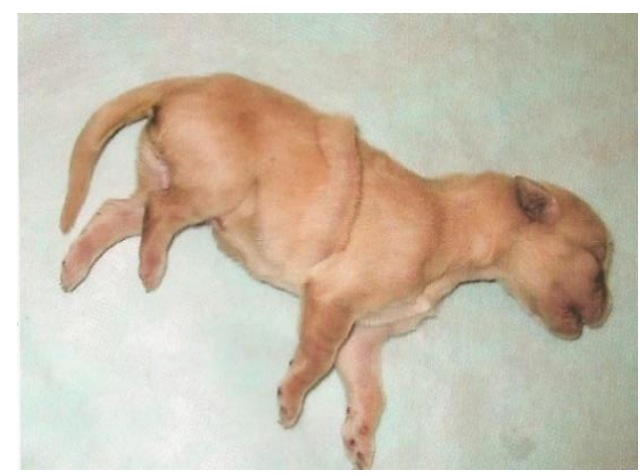

Figura 14. Neonato apresentando grave quadro de desidratação podendo ser visto através da avaliação do turgor cutâneo. Fonte: Sorribas (2007).

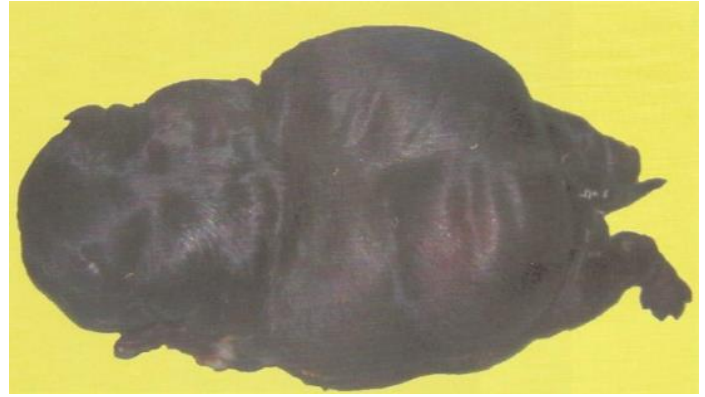

Figura 16: Filhote de labrador apresentando edema congênito letal sendo evidente o acúmulo de líquido em todo o corpo. Fonte: Sorribas (2007)

\section{Farmacologia em neonatos caninos}

Feitosa (2014) sustenta que a escolha de fármacos para administrar em recém-nascidos deve ser feita de forma criteriosa e com ajuste de dosagem para que não ocorra nenhum tipo de intoxicação, já que a falta de maturidade dos sistemas hepático e renal tem relação direta com a metabolização e excreção desses fármacos.

Dissertando sobre a fisiologia renal do neonato canino, Feitosa (2014) afirma que a nefrogênese permanece incompleta até a terceira semana após o nascimento devido seus rins apresentarem morfologia e funcionalidade imaturas. Diante das particularidades urinárias do neonato canino pode-se encontrar na sua urinálise alterações fisiológicas como diminuição da densidade urinária e presença de proteínas, glicose e aminoácidos. Quando se trata de medicação para neonatos, deve-se ter muito cuidado com qual medicamento usar, quanto administrar e com que frequência utilizar. O metabolismo hepático incompleto faz com que o neonato apresente um mau funcionamento do citocromo P450 de forma fisiológica, este sendo um grupo de enzimas que atua no metabolismo da maioria dos medicamentos tornando-os substâncias mais polares e hidrossolúveis para serem mais bem aproveitadas, que só será maturado por volta dos cinco meses de vida (Apparício et al., 2015; Crespilho et al., 2006). Recomenda-se que a dose para cães adultos seja reduzida de 30 a $50 \%$ quando administrada em filhotes, ou que se aumente o intervalo entre as dosagens de 2 a 4 horas (Papich, 2012). 
Dentre os grupos de antibióticos de escolha considerados seguros para uso em neonatos estão os beta-lactâmicos, e dentre eles estão penicilinas, cefalosporinas e amoxiciclina com ou sem clavulanato (Papich, 2012). Segundo Kustritz (2011), o aumento do pH gástrico, a diminuição da velocidade gastrointestinal, o tempo de trânsito e a diminuição do fluxo sanguíneo intestinal dos neonatos faz com que os medicamentos administrados por via oral sejam absorvidos diferentemente de animais adultos.

Quadro 3. Efeitos adversos de fármacos quando administrados em neonatos caninos.

\begin{tabular}{ll}
\hline Fármacos & Efeitos adversos em neonatos \\
\hline Quinolonas & Tóxica para cartilagem do filhote canino \\
Trimetoprim com ou sem sulfonamida & $\begin{array}{l}\text { Ceratoconjuntivite seca, reações cutâneas, anemia, trombocitopenia e reações } \\
\text { alérgicas, incluindo hipersensibilidades tipo II e III, e artropatias }\end{array}$ \\
Aminoglicosídeos e cloranfenicol & $\begin{array}{l}\text { Nefrotoxicidade } \\
\text { Tecão quelante de cálcio ósseo podendo levar a deformidades ósseas, displasia } \\
\text { Tetraciclinas }\end{array}$ \\
\hline
\end{tabular}

Fonte: adaptado de Ftitzgerard \& Newquist(2011).

O Quadro 3 mostra os grupos farmacológicos tóxicos para neonatos, dentre eles as quinolonas como a enrofloxacina que é considerada tóxica para a cartilagem do filhote canino, principalmente entre $4 \mathrm{e}$ 28 semanas de vida. Trimetoprim associado com sulfonamida podem levar a uma ceratoconjuntivite seca, reações cutâneas, anemia, trombocitopenia e reações alérgicas, incluindo hipersensibilidades tipo II e III, e artropatias. Os aminoglicosídeos e o cloranfenicol que estão associados à nefrotoxicidade, não devem ser utilizados em animais jovens devido a sua imaturidade do sistema renal, além do segundo ser capaz de causar supressão da medula óssea. As tetraciclinas são contraindicadas devido a sua ação quelante de cálcio ósseo podendo levar a deformidades ósseas, displasia dentária e distúrbios do crescimento (Ftitzgerard \& Newquist, 2011).

Os recém-nascidos são muito suscetíveis a efeitos adversos, uma vez que suas vias de metabolização das drogas são imaturas, além da sua permeabilidade intestinal ser aumentada, e como consequência disso, a captação de moléculas tóxicas se torna maior (Ftitzgerard \& Newquist, 2011).

\section{Reanimação neonatal}

A reanimação neonatal (Figura 17) é adotada em partos feitos por cesariana eletiva, ou quando a fêmea que pariu não apresenta instinto materno para reanimar naturalmente os filhotes pela lambedura (Sorribas, 2007). Segundo Moon et al. (2001), cerca de 5\% dos recém-nascidos precisam de algum tipo de intervenção com o objetivo de corrigir a hipóxia, otimizar a circulação, manter a temperatura neonatal e as atividades metabólicas como suporte para a vida. Logo após o nascimento, deve-se realizar o corte e a desinfecção do cordão umbilical, fazer o delivramento das vias aéreas superiores retirando os envoltórios fetais da região e líquidos fetais com o auxílio da pera de sucção (Peterson \& Kutzler, 2011). Isso deve ser feito intercalado com a fricção na região torácica com o auxílio de um pano. Realizar a auscultação cardíaca que deve ser superior a 200 batimentos por minuto (bpm). Em seguida, realizar a higienização e aquecimento do neonato, podendo utilizar secador de cabelo para auxiliar nessa parte. Após regularizar a temperatura do neonato, realizar o escore Ápgar (Sorribas, 2007).

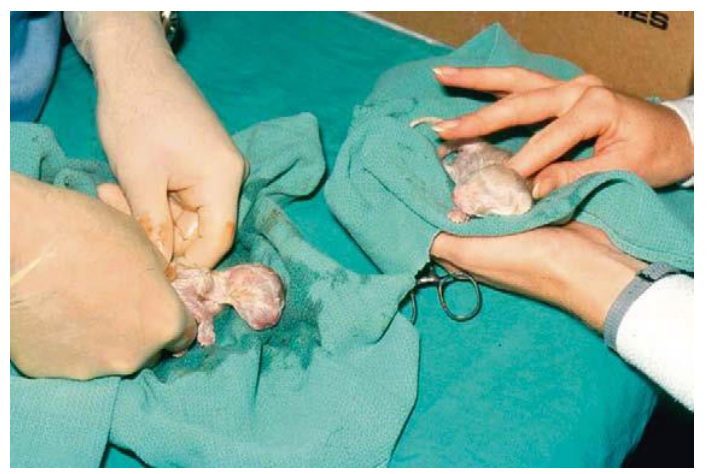

Figura 17. Reanimação neonatal. Fonte: McMichael (2011).

O escore Ápgar tem como objetivo avaliar de forma rápida a vitalidade neonatal e identificar rapidamente neonatos que necessitam de cuidados intensivos a fim de reduzir a mortalidade neonatal. 
Recebe esse nome por sua criadora médica obstétrica Virginia Apgar em 1953 (Casey et al., 2001; Finster \& Wood, 2005; Vassalo et al., 2005).

Conforme Silva et al. (2008), o escore Ápgar é medido após 5 e 60 minutos avaliando parâmetros como frequência cardíaca, esforço respiratório, tônus muscular, irritabilidade reflexa e coloração da mucosa gengival, atribuindo-lhes notas de 0 a 2, conforme Quadro 4. A somatória das notas em cada parâmetro varia de 0 a 10 dentro do escore Ápgar. Notas de 0 a 3 classificam o neonato em estado grave, notas de 4 a 6 identificam o neonato em estado moderado e notas de 7 a 10 mostra o neonato hígido logo após o nascimento. As Figuras 18, 19 e $\underline{20}$ ilustram exemplos de resultados do escore Ápgar logo após o nascimento de neonatos caninos (Vassalo et al., 2005).

Quadro 4. Parâmetros adotados para o escore Ápgar de vitalidade neonatal em Medicina Veterinária.

\begin{tabular}{llll}
\hline & \multicolumn{3}{c}{ Escore } \\
\cline { 2 - 4 } & 0 & 1 & 2 \\
\hline Frequência Cardíaca & Ausente & Bradicárdica. FC $<180 \mathrm{bpm}$ & Presente e normal. FC = 180-250 bpm \\
Esforço Respiratório & Ausente & Irregular & Regular e vocalização \\
Tônus muscular & Flacidez & Alguma flexão & FR = 15-40 mpm \\
Irritabilidade Reflexa & Ausente & Algum movimento & Flexão \\
Coloração de mucosas & Cianose e palidezCianose & Hiperatividade \\
\hline
\end{tabular}

Escore 7 a $10=$ bom. Escore 4 a $6=$ regular (há necessidade de assistência neonatal). Escore 0 a 3 = ruim (há necessidade de assistência neonatal intensiva)

Fonte: Silva et al. (2008) e Kustritz (2011).
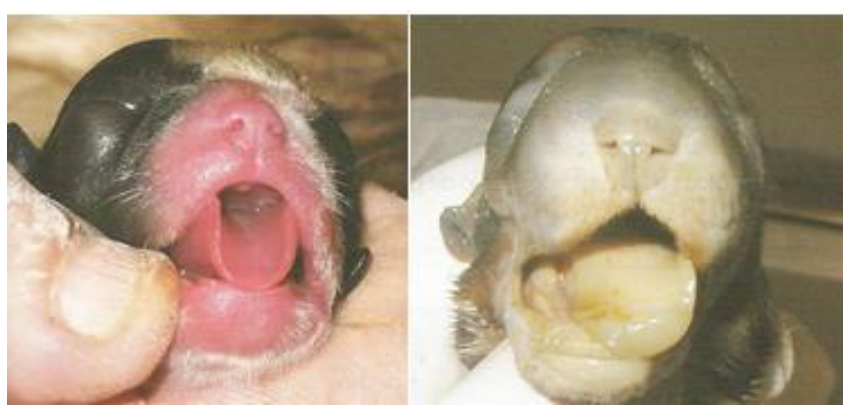

Figura 18. A esquerda um filhote com mucosas de coloração rósea intensa, o que garante sua higidez e pontuação 2 no escore Ápgar. À direita, um filhote com mucosas de coloração ictérica indicando pontuação 0 no escore Ápgar. Fonte: Sorribas (2007).

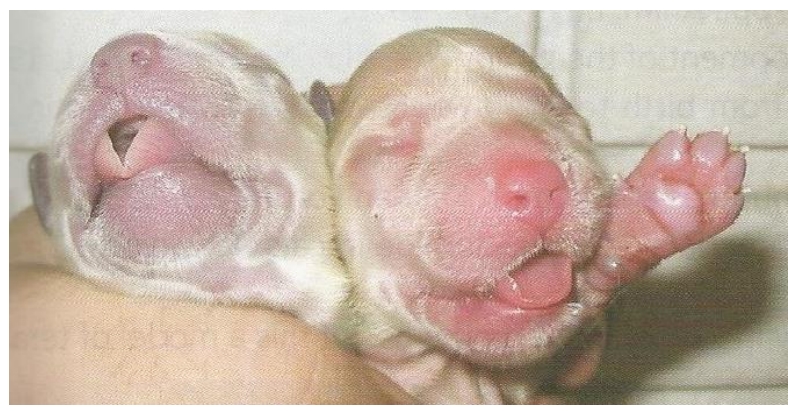

Figura 19. A esquerda um neonato com mucosas de coloração cianótica, o que confere pontuação 0 no escore Ápgar. À direita, um neonato com mucosas de coloração rósea garantindo sua pontuação 2 no escore Ápgar. Fonte: Sorribas (2007).

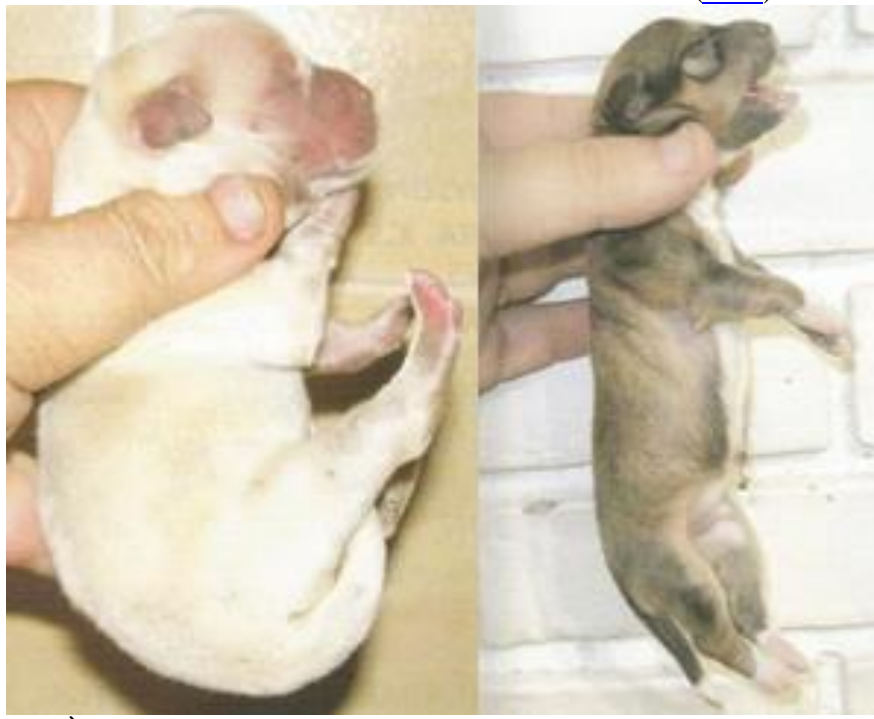

Figura 20. À esquerda um neonato com bom tônus muscular e movimento ativo, o que confere pontuação 2 no escore Ápgar. À direita, um neonato com tônus muscular flácido, garantindo sua pontuação 0 no escore Ápgar. Fonte: Sorribas (2007). 
A reanimação neonatal intensiva é usada em neonatos que mesmo após a assistência pós-parto permanecem cianóticos, apresentam bradicardia, apneia ou respiração agônica, entre outras condições como a anasarca generalizada. Nestes casos é indicado o uso do ponto Jen Chung de acupuntura VG26, inserindo uma agulha de pequeno calibre e rotacionando-a em sentido horário, promovendo um estímulo respiratório complementar para auxiliar o neonato na adaptação respiratório ao ambiente extrauterino (Peterson \& Kutzler, 2011).

\section{Considerações finais}

Cuidar de neonatos caninos é um grande desafio, pois exige conhecimento básico de todo o manejo neonatal de forma adequada, abordando as suas particularidades fisiológicas, onde estão contidos os segredos para que não se perca nenhum neonato visando promover a sua saúde por meio de práticas de higiene e fornecimento de tudo que estes animais precisam na primeira fase de sua vida, ocasionando a queda da mortalidade neonatal, tendo em vista que ela não deve ser considerada algo normal e esperado.

Uma forma de auxílio ao médico veterinário para adquirir conhecimento sobre a fisiologia neonatal canina seria o estímulo do estudante de medicina veterinária dentro do ambiente acadêmico, e o desenvolvimento de habilidades pelos cursos para que os médicos veterinários se tornem aptos a trabalhar com isso.

\section{Referências}

Angulo, S. M. (2012). Enfermedades de los neonatos. Revista de Colvema, 6-12.

Apparício, M., Vicente, \& Russiano, W. R. (2015). Reprodução e obstetrícia em cães e gatos. MedVet, 2, 9-13.

Barreto, C. S. (2003). Avaliação de filhotes caninos. In Faculdade de Medicina Veterinária e Zootecnia: Vol. PhD. Universidade de São Paulo.

Casey, B. M., McIntire, D. D., \& Leveno, K. J. (2001). The continuing value of the Apgar score for the assessment of newborn infants. New England Journal of Medicine, 344(7), 467-471.

Chaves, M. S. (2011). Neonatologia em cães e gatos: Aspectos relevantes da fisiologia e patologiarevisão de literatura e relato de caso de Diprosopo Tetraoftalmo (pp. 1-41). Universidade Federal de Minas Gerais.

Crespilho, A. M., Martins, M. I. M., Souza, F. F., Lopes, M. D., \& Papa, F. O. (2006). Abordagem terapêutica do paciente neonato canino e felino: 1. Particularidades farmacocinéticas. Revista Brasileira de Reprodução Animal, 30(1/2), 3-10.

Domingos, T. C. S., Rocha, A. A., \& Cunha, I. C. N. (2008). Cuidados básicos com a gestante e o neonato canino e felino: revisão de literatura. Jornal Brasileiro de Ciência Animal, 1(2), 94-120.

Feitosa, F. L. F. (2014). Semiologia veterinária: A arte do diagnóstico. Grupo Gen-Editora Roca Ltda. Finster, M., \& Wood, M. (2005). The Apgar score has survived the test of time. Anesthesiology, 102(4), 855-857.

Ftitzgerard, K. T., \& Newquist, K. L. (2011). Husbandry of the neonate. In M E Peterson \& M. A. Kutzler (Eds.), Small animal pediatries (pp. 44-52). Sauders Elsevier. https://doi.org/10.1016/B9781-4160-4889-3.00006-1.

Grundy, S. A. (2006). Clinically relevant physiology of the neonate. The Veterinary Clinics of North America. Small Animal Practice, 36(3), 443-459.

IBGE - Instituto Brasileiro de Geografia e Estatística. Pesquisa nacional de saúde de 2013: acesso e utilização dos serviços de saúde, acidentes e violências: Brasil, grandes regiões e unidades da federação / IBGE, Coordenação de Trabalho e Rendimento. - Rio de Janeiro, 2015. Disponível em: $<$ https://www12.senado.leg.br/institucional/omv/entenda-aviolencia/pdfs/IBGE_PesquisaNacionaldeSaude2013>. Acesso em: 10 set. 2020.

Jones, R. L. (1987). Special considerations for appropriate antimicrobial therapy in neonates. Veterinary Clinics of North America: Small Animal Practice, 17(3), 577-602. https://doi.org/10.1016/S01955616(87)50055-9.

Kustritz, M. V. R. (2011). Clinical canine and feline reproduction: evidence-based answers. John Wiley $\&$ Sons. 
Landim-Alvarenga, F. C., Prestes, N. C., \& Santos, T. C. M. (2017). Manejo do neonato. Obstetrícia veterinária. Guanabara Koogan.

Lawler, D. F. (2008). Neonatal and pediatric care of the puppy and kitten. Theriogenology, 70(3), 384392. https://doi.org/10.1016/j.theriogenology.2008.04.019.

Lopes, S. T. A., Biondo, A. W., \& Santos, A. P. (2007). Manual de patologia clínica veterinária (Vol. 1). Universidade Federal de Santa Maria.

Lourenço, M. G. L. (2015). Cuidados com neonatos e filhotes. In M. M. Jericó, J. P. A. Neto, \& M. M. Kogika (Eds.), Tratado de medicina interna de cães e gatos (pp. 1153-1481). Editora Roca.

Lourenço, M. L. G., \& Machado, L. H. A. (2013). Características do período de transição fetal-neonatal e particularidades fisiológicas do neonato canino. Revista Brasileira de Reprodução Animal, 37(4), 303-308.

Macintire, D. K., Drobatz, K. J., Haskins, S. C., \& Saxon, W. D. (2007). Emergência e cuidados intensivos em pequenos animais. Manole.

Martins, R. R. (2005). Hemograma, proteinograma e enzima gama-glutamil transferase de cães neonatos, do $3^{\circ}$ ao $45^{\circ}$ dia de vida, sob a ação da idade e da suplementação com luteína. Universidade Estadual Paulista.

McGavin, D., \& Zachay, J. F. (2013). Bases da patologia em veterinária. Elsevier Brasil.

McMichael, M. A. (2011). Emergency and critical care issues. In M E Peterson \& M. A. Kutzler (Eds.), Samll animal pediatrics: the first 12 months of life (pp. 161-167). Sauders Elsevier.

Miller, J. B. (2011). Approach to the febrile patient. In M E Peterson \& M. A. Kutzler (Eds.), Small animal the first 12 months of life (pp. 161-167). Sauders Elsevier. https://doi.org/10.1016/B978-14160-4889-3.00020-6.

Moon, P. F., Massat, B. J., \& Pascoe, P. J. (2001). Neonatal critical care. Veterinary Clinics of North America: Small Animal Practice, 31(2), 343-367. https://doi.org/10.1016/S0195-5616(01)50209-0.

Nelson, R. W., \& Couto, C. G. (2015). Medicina interna de pequenos animais (Issue 1). Elsevier Editora.

Papich, M. G. (2012). Manual Saunders de Terapia Veterinária. Elsevier Health Sciences Brazil.

Peterson, Michael E, \& Kutzler, M. (2011). Small animal pediatrics: the first 12 months of life. Elsevier Health Sciences.

Prats, A., Prats, A., García, F., Dumon, C., Martí, S., \& Coll, V. (2005). Neonatologia e pediatria canina e felina. Interbook.

Prendergast, H. (2011). Nutritional requirements and feeding of growing puppies and kittens. In M E Peterson \& M. A. Kutzler (Eds.), Small animal pedriatries: the first 12 months of life (pp. 58-66). Sauders Elsevier. https://doi.org/10.1016/B978-1-4160-4889-3.00008-5.

Ruaux, C. (2011). The respiratory system. In M E Peterson \& M. A. Kutzler (Eds.), Small animal pediatries: the first 12 months (pp. 328-339). Saunders Elsevier.

Silva, L. C. G., Lúcio, C. F., Veiga, G. A. L., Rodrigues, J. A., \& Vannucchi, C. I. (2008). Avaliação clínica neonatal por escore Apgar e temperatura corpórea em diferentes condições obstétricas na espécie canina. Revista Portuguesa de Ciências Veterinárias, 103(567/568), 165-170.

Sorribas, C. E. (2007). Atlas de neonatologia y pediatria en caninos. Inter-medica.

Souza, T. D., Silva Mol, J. P., Paixão, T. A., \& Santos, R. L. (2017). Mortalidade fetal e neonatal canina: etiologia e diagnóstico. Revista Brasileira de Reprodução Animal, 41(2), 639-649.

Tønnessen, R., Borge, K. S., Nødtvedt, A., \& Indrebø, A. (2012). Canine perinatal mortality: a cohort study of 224 breeds. Theriogenology, 77(9), 1788-1801. https://doi.org/10.1016/j.theriogenology.2011.12.023.

Vassalo, F. G., Silva, L. P. da, Lourenço, M. L. G., \& Chiacchio, S. B. (2005). Apgar, V. A proposal for a new method of evaluation of the newborn infant. Revista Brasileira de Reprodução Animal, Currents R, 260-267.

Zachary, J. F., McGavin, D., \& McGavin, M. D. (2012). Bases da patologia em veterinária. Elsevier Brasil.

Histórico do artigo:

Recebido: 3 de março de 2021

Aprovado: 16 de abril de 2021.
Licenciamento: Este artigo é publicado na modalidade Acesso Aberto sob a licença Creative Commons Atribuição 4.0 (CC-BY 4.0), a qual permite uso irrestrito, distribuição, reprodução em qualquer meio, desde que o autor e a fonte sejam devidamente creditados. 